\title{
Differences in and Prognostic Value of Quality of Life Data in Rectal Cancer Patients with and without Distant Metastases
}

\author{
Fabian Frank, Markus Hecht $\mathbb{D}$, Florian Loy, Sandra Rutzner, Rainer Fietkau and Luitpold Distel *(D) \\ Department of Radiation Oncology, Universitätsklinikum Erlangen, \\ Friedrich-Alexander-Universität of Erlangen-Nürnberg (FAU), D-91054 Erlangen, Germany; \\ fabian.frank@fau.de (F.F.); markus.hecht@uk-erlangen.de (M.H.); Flo-loy@web.de (F.L.); \\ Sandra.rutzner@uk-erlangen.de (S.R.); rainer.fietkau@uk-erlangen.de (R.F.) \\ * Correspondence: Luitpold.Distel@uk-erlangen.de; Tel.: +49-9131-853-2312; Fax: +49-9131-853-9335
}

Citation: Frank, F.; Hecht, M.; Loy, F.; Rutzner, S.; Fietkau, R.; Distel, L. Differences in and Prognostic Value of Quality of Life Data in Rectal Cancer Patients with and without Distant Metastases. Healthcare 2021, 9, 1. https://doi.org/10.3390/ healthcare 9010001

Received: 26 November 2020 Accepted: 18 December 2020 Published: 22 December 2020

Publisher's Note: MDPI stays neutral with regard to jurisdictional claims in published maps and institutional affiliations.

Copyright: () 2020 by the authors. Licensee MDPI, Basel, Switzerland. This article is an open access article distributed under the terms and conditions of the Creative Commons Attribution (CC BY) license (https: / / creativecommons.org/ licenses/by/4.0/).
Abstract: (1) Background: Individualization of treatment is a major challenge in oncology and requires a variety of predictive and prognostic parameters. In addition to tumor biology analyses, baseline health-related quality of life might be a valid tool to predict overall survival. This study was conducted to evaluate the prognostic relevance of baseline quality of life data in patients with rectal cancer. In this context, differences between patients with and without distant metastases were of particular interest. (2) Methods: Our cohort included 258 patients with rectal cancer treated in the radiotherapy department of the University Hospital Erlangen. Patients completed the European Organisation for Research and Treatment of Cancer (EORTC) core quality of life questionnaire (QLQ C30) and colorectal cancer questionnaire (CR38). Clinical and survival data were provided by the Gießener Tumor Documentation System (GTDS) of the Comprehensive Cancer Center Erlangen-EMN (CCC, Friedrich-Alexander University Erlangen-Nuremberg, Erlangen, Germany). Statistical analyses were performed using Kaplan-Meier analyses and univariate and multivariate Cox regression. (3) Results: A cohort of 258 patients with rectal adenocarcinoma was analyzed including 50 patients (19.4\%) with metastatic disease. No differences were observed between patients with and without distant metastases in most areas of quality of life studied, with the exception of physical function, loss of appetite, chemotherapy side effects and weight loss. Gender, baseline physical function, sexual function, diarrhea, and weight loss over time had a prognostic value in the entire cohort. Appetite loss was an additional prognostic parameter in patients with distant metastases. (4) Conclusions: The quality of life of patients with metastatic disease differed only slightly from non-metastatic patients. Health-related quality of life data provide prognostic information for patients with rectal cancer.

Keywords: colorectal cancer; metastatic disease; patient reported outcomes; health related quality of life; prognostication

\section{Introduction}

Health-related quality of life (HRQoL) is a concept that has gained increasing importance in cancer research in recent years. Both as a valid endpoint in studies [1-3] and as a prognostic tool itself [4-6]. Overall survival (OS) has long been considered as the most relevant endpoint in cancer studies. Over time, other tumor-related outcomes such as progression-free survival or disease-free survival have been introduced, which are not necessarily of critical importance to the patients themselves [7]. Patients provide a relevant perspective on their own disease, quality of life, and symptom burden. Studies have concluded that assessment of these patient-reported outcomes (PROs) is more accurate than external measurement by physicians or other health professionals [8]. The prognostic implications of HRQoL data have been widely reported for colorectal cancer [4,5,9-11] and other cancer entities, including head and neck [12], breast [13-15], and brain [16]. Standard therapy for rectal carcinoma includes neoadjuvant radiochemotherapy $[17,18]$. This therapy is locally very efficient and thus leads to a local cure. Unfortunately, 20\% to 
$35 \%$ of patients have metastatic disease at the time of diagnosis $[19,20]$ and $20 \%$ up to $50 \%$ of patients develop metastases during the course of the disease [21]. These patients have a very poor prognosis. Patients with metastatic disease have a five-year survival of $13.1 \%$ compared to $90.1 \%$ for non-metastatic patients [22]. The aim of this study was to investigate HRQoL as a potential predictor of OS in our patient cohort. It was of interest to investigate whether patients with metastatic disease suffered more than patients who were cured by a treatment regimen including neoadjuvant radiochemotherapy.

\section{Materials and Methods}

\subsection{Patients}

This open cohort study combines quality of life data collected consecutively between 2005 and 2017 at the radiotherapy department of the University Hospital Erlangen. Data collection was prospective and a total of 258 patients with rectal cancer were included. Inclusion criteria were confirmed rectal cancer diagnosis, treatment with combined radiochemotherapy and written informed consent to participate. All patients received systemic chemotherapy and were treated with 50.4 Gy of ionizing radiation. Data on clinicopathologic factors, including TNM Classification of Malignant Tumors (TNM), Union internationale contre le cancer (UICC) classification, chemotherapy, surgery, radiation, and vital status were obtained by the Comprehensive Cancer Center Erlangen-EMN. Missing clinical data were collected from electronic medical records. Demographic and basic disease characteristics are listed in Table 1.

\subsection{Treatment}

The radiation treatment regimen was a four-field box technique with three-dimensional conformal radiotherapy. Patients were treated with daily doses of $1.8 \mathrm{~Gy}$ up to a total dose of $50.4 \mathrm{~Gy}, 30$ patients also received hyperthermia. One hundred and forty-nine nonmetastatic patients received neoadjuvant treatment, 12 received adjuvant treatment, and 22 were not surgically treated. After completion of radiochemotherapy, patients were treated with a total mesorectal resection of the cancer. The most commonly used concurrent chemotherapy combination was 5-FU and oxaliplatin. The remaining patients received similar treatment regimens including 5-FU solo, 5-FU + capecitabine, 5-FU + antibody, $5-\mathrm{FU}+$ cisplatin or 5-FU + irinotecan. Metastatic patients typically received FOLFOX, FOLFIRI or FOLFOX-IRI, in some cases in combination with antibodies.

\subsection{Quality of Life}

Quality of life data were prospectively collected using the EORTC QLQ C30 [23] and EORTC QLQ CR38 [24] questionnaires at various time points throughout the therapy. For this study, the baseline score obtained immediately before therapy and the post-treatment score obtained in the first week after the end of therapy were considered. The EORTC QLQ C30 consists of 30 items and assesses oncological patients multidimensionally over 10 scores. Functional scores are physical, role, cognitive, and emotional function. Symptom scores are pain, fatigue, nausea, and vomiting. Other scores are global quality of life and various derived from single items: dyspnea, insomnia, appetite loss, constipation, diarrhea, and financial difficulties. Higher values in the functional scores indicate better quality of life, while higher values in the symptom scores indicate more symptoms and thus a lower quality of life. The EORTC QLQ CR38 consists of 38 items covering symptoms and side-effects related to various treatment modalities, body image, sexuality, and future perspective. All QoL scores were calculated according to the official EORTC manuals.

\subsection{Statistics}

Unpaired $t$-tests were performed for all functional, symptom, and rectal specific scores to detect differences between metastatic and non-metastatic patients. Levene's test for equal variance and Cohen's D were calculated for each variable. Significant findings 
were analyzed as described below. To check other staging variables $\mathrm{T}$ and $\mathrm{N}$ status were examined in the same method.

Table 1. Demographic and basic disease characteristics.

\begin{tabular}{|c|c|c|}
\hline Risk Factor & Total No. & No. (\%) \\
\hline Age (years) ${ }^{1}$ & 258 & $67.4(11.6)$ \\
\hline Gender & 258 & \\
\hline Male & & $191(74)$ \\
\hline Female & & $67(26)$ \\
\hline Status & 258 & \\
\hline Alive & & $184(71.3)$ \\
\hline UICC & 258 & \\
\hline $\mathrm{I}$ & & $21(8.1)$ \\
\hline II & & 49 (19) \\
\hline III & & $141(54.7)$ \\
\hline IV & & 47 (18.2) \\
\hline TNM: cT & 258 & \\
\hline 1 & & $6(2.3)$ \\
\hline 2 & & $30(11.6)$ \\
\hline 3 & & $162(62.8)$ \\
\hline 4 & & $60(23.3)$ \\
\hline TNM: cN & 255 & \\
\hline$x$ & & $3(1.2)$ \\
\hline 0 & & $70(27.1)$ \\
\hline 1 & & $135(52.3)$ \\
\hline 2 & & $50(19.4)$ \\
\hline TNM: cM & 233 & \\
\hline X & & $25(9.7)$ \\
\hline 0 & & $183(70.9)$ \\
\hline 1 & & $50(19.4)$ \\
\hline TNM: pL & 214 & \\
\hline$x^{1}$ & & $44(17.1)$ \\
\hline 0 & & $172(66.7)$ \\
\hline 1 & & $42(16.3)$ \\
\hline TNM: pV & 212 & \\
\hline$x^{1}$ & & $46(17.8)$ \\
\hline 0 & & $202(78.3)$ \\
\hline 1 & & $10(3.9)$ \\
\hline
\end{tabular}

${ }^{1}$ For Age, No. (\%) are mean (standard deviation).

\subsection{Survival Analysis}

The clinical outcome considered in this trial was overall survival, defined as time until tumor related death. In the absence of death confirmation OS was censored at the date of last contact. Univariate and multivariate Cox regression models were used for the analysis. The variables used were QoL functional scores, QoL symptom scores, QoL rectum specific scores, and gender. First, the risks for the quality of life indicated prior to therapy were calculated and defined as "baseline scores". Hazard ratios for baseline QoL data were calculated for every $20 \%$ change [25]. Changes between baseline and post-treatment QoL assessments were calculated as dichotomized variable (deterioration yes or no) and defined as "change scores". All Cox regressions were calculated age adjusted. First univariate Cox regression was performed with significance level of 0.05 . All identified variables were then tested in multivariate Cox regression. In a first block, age and gender integrated into the model using the enter method. In a second block, identified variables were then tested as stepwise backwards model with entry and removal levels of 0.05 and 0.10 , respectively. The proportional hazards assumption was tested by visual inspection of the log-minus-log curves and was found to be satisfactory for all multivariate covariates. Kaplan-Meier survival plots were used for survival estimation and compared using the 
log rank test. For balanced group creation, baseline variables were split at median [11]. All statistical analysis was performed with SPSS 26 (IBM, Armonk, NY, USA).

\section{Results}

Due to low response rate female sexual problems (missing 254 of 258), stoma problems (missing 225 of 258), and sexual satisfaction (missing 189 of 258) were not included in the analysis.

\subsection{Baseline Characteristics}

A total of 258 patients with rectal cancer were included. The median follow-up time was 64.4 months (range 12-152 months). Overall survival for all patients was $66.6 \%$ at 72 months (Figure 1A). Patients had mainly advanced cancer (T3 stage 162/62.8\%) with affected lymph nodes (N1 stage 135/52.3\%) and distant metastasis (M1 stage 50/19.4\%) (Table 1). The median age was 67.4 years and $74 \%$ of patients were male.

\subsection{Patients Suffering from Metastases}

In our cohort, 50 patients $(19.4 \%)$ had a metastatic disease. Metastatic status increased the relative hazard of dying by $281 \%(95 \% \mathrm{CI}=2.25-6.47, p<0.001)$. Overall survival at 6 years was $74.6 \%$ in the M0 group compared to $38.9 \%$ in the M1 group. (Figure 1C). Box plots of the individual EORTC domains are presented in Figure 2. Most scores of patients who had a metastatic disease were not different from patients with cured rectal cancer. Physical function, appetite loss, chemo side effects for baseline scores, and weight loss for change scores differed significantly by unpaired $t$-test (Table 2 marked with * in Figure 2). In addition, patients with tumor stage greater than or equal to T3 showed significant differences in some categories, namely nausea and vomiting (mean difference +4.58 ), future prospect (mean difference $+13,6$ ), and defecation problems (mean difference $+4,4$ ). It should be noted that 44 of 50 metastatic patients were also in this group. Positive $\mathrm{N}$ status did not result in a significant difference in any HRQoL variable.

Appetite loss is the only QoL score of patients with metastases that is clearly associated with survival in both univariate and multivariate analyses (Table 3). The Kaplan-Meier plot for appetite loss in the metastatic patients (Figure 3) shows similar results to those of the entire cohort (Figure 4D).

\subsection{Prognostic Value of Baseline EORTC QLQ C30 and CR38 Data in the Whole Cohort}

Cox regression analyses were performed for baseline quality of life (Table 4). In univariate analysis physical function, role function, fatigue, nausea and vomiting, pain, dyspnea, appetite loss, male sexual problems, and weight loss were significantly associated with survival. Global health score was not associated with survival. All of these hazard ratios indicate a higher survival for patients with higher functional scores and shorter survival for patients with higher symptom scores. In multivariate analysis, physical function clearly remained a favorable influential factor as did gender. Male patients had a $46 \%$ higher risk of death. The hazard ratio for physical function indicates that for every $20 \%$ increase, the relative hazard of dying decreased by $29 \%(95 \% \mathrm{CI}=0.57-0.88)$. The other variables remained nonsignificant in the multivariate model. Kaplan-Meier survival plots display differences in overall survival between groups for role function $(p=0.048)$ (Figure $4 \mathrm{~A})$, fatigue $(p=0.006)$ (Figure $4 \mathrm{~B})$, pain $(p=0.018)$ (Figure $4 \mathrm{C})$, and appetite loss $(p=0.003)$ (Figure 4D).

\subsection{Prognostic Value of Change EORTC QLQ C30 and CR38 Data in the Whole Cohort}

Cox regression analysis was performed for change scores (Table 5). In univariate analysis diarrhea, sexual function, and weight loss were significant for survival. Ageadjusted multivariate analysis identified diarrhea $(\mathrm{HR}=0.34,95 \% \mathrm{CI}=0.128-0.93, p=0.035)$, sexual function $(\mathrm{HR}=3.13,95 \% \mathrm{CI}=1.16-8.46, p=0.024)$, and weight loss ( $\mathrm{HR}=0.26$, $95 \% \mathrm{CI}=0.09-0.79, p=0.017$ ) as significant predictors of survival. HRs indicates worse 
survival for deterioration in sexual function and longer survival for worsening in diarrhea and weight loss. Kaplan-Meier survival plots show differences between groups for sexual function (Figure 5A), weight loss (Figure 5B) and diarrhea (Figure 5C).

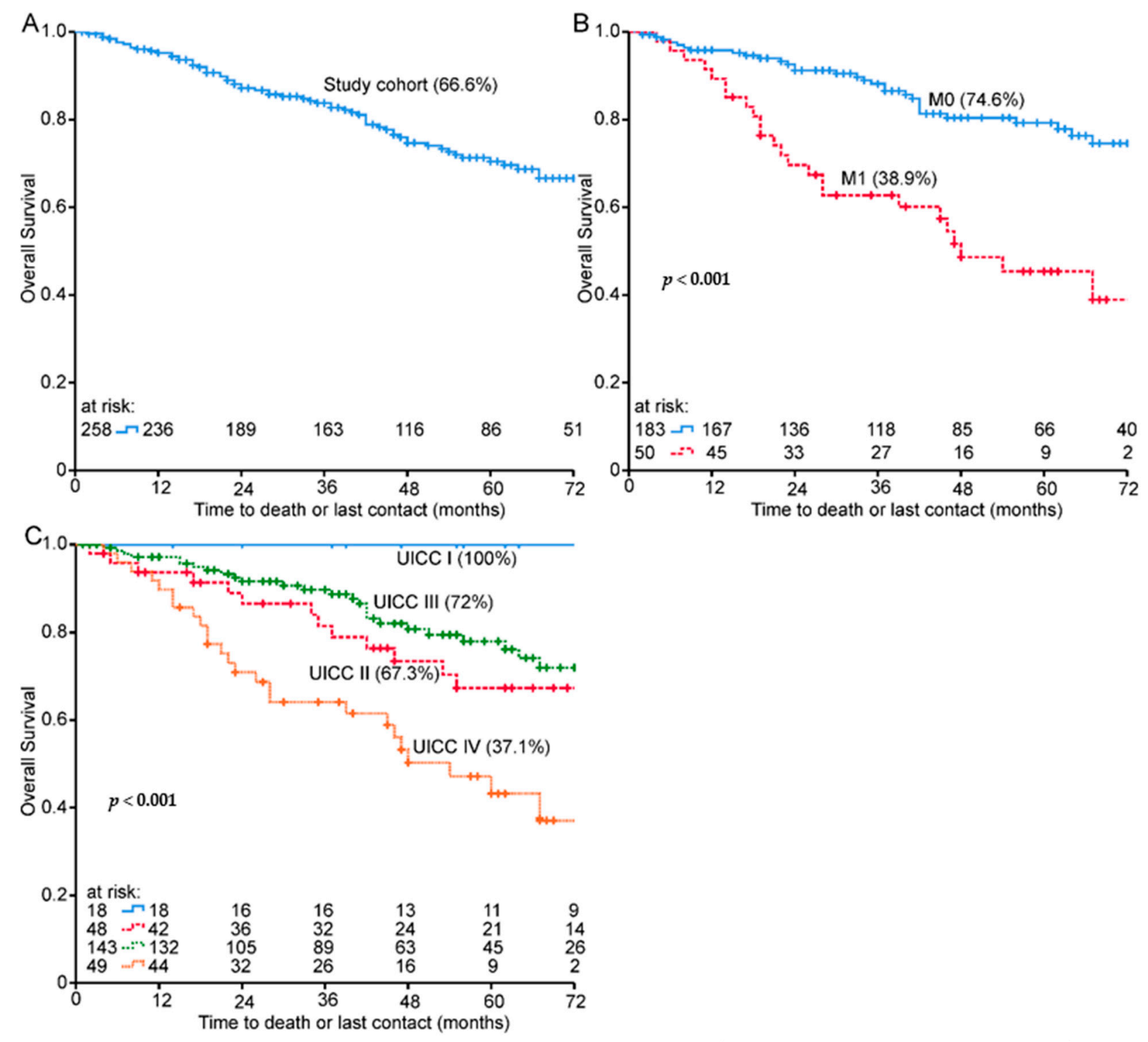

Figure 1. Kaplan-Meier plots for (A) overall survival of the entire cohort, (B) TNM: distant metastasis M and (C) stage UICC I-IV. Seventy-two-month overall survival \% in brackets. 

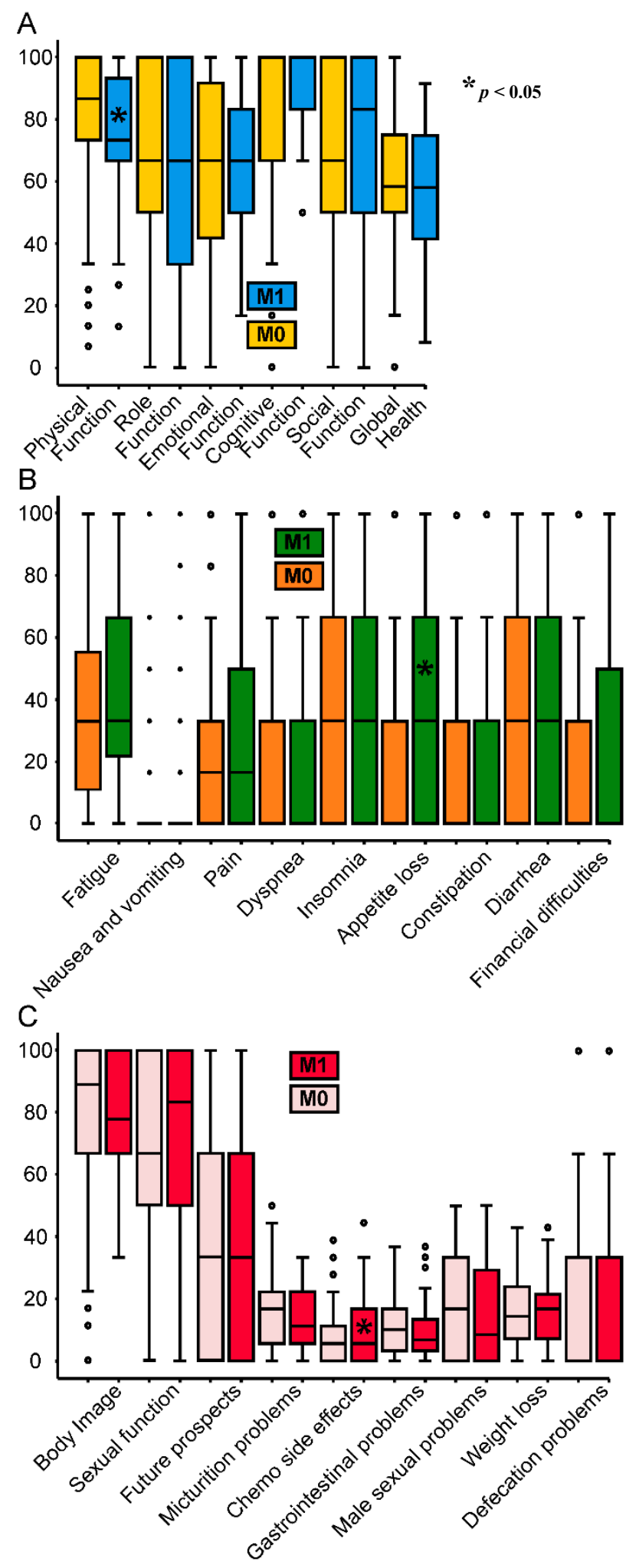

Figure 2. Side-by-side box plots M0 $(n=183)$ vs. M1 $(n=50)$ of baseline (A) QLQ C30 functional scores M0 (yellow), M1 (blue), (B) QLQ C30 symptom scores M0 (orange), M1 (green), (C) QLQ CR38 scores M0 (pale pink), M1 (red), * marks domains significant in an unpaired $t$-test. 
Table 2. M0 compared to M1 for quality of life baseline and change scores using the $t$-test.

\begin{tabular}{ccccc}
\hline Risk Factor $^{\mathbf{1}}$ & $\begin{array}{c}\boldsymbol{p} \text {-Value } \\
\text { (2-Tailed) }\end{array}$ & $\begin{array}{c}\text { Mean } \\
\text { Difference }\end{array}$ & 95\% CI & Cohen's d \\
\hline $\begin{array}{c}\text { Baseline } \\
\text { Physical }\end{array}$ & 0.036 & 7.78 & $0.51-15.05$ & 0.286 \\
$\quad$ function & 0.008 & -15.35 & $-26.62-4.09$ & 0.716 \\
$\begin{array}{c}\text { Appetite loss } \\
\text { Chemotherapy }\end{array}$ & 0.015 & -4.66 & $-8.37-0.95$ & 0.657 \\
$\begin{array}{c}\text { Side Effects } \\
\text { change }\end{array}$ & & & & \\
Weight loss & 0.008 & 18.33 & $4.91-31.75$ & 0.797 \\
\hline${ }^{\text {significant only. }}$ & & &
\end{tabular}

Table 3. Overall survival of age-adjusted hazard ratios for M1 patients baseline and change scores QLQ C30 and QLQ CR38.

\begin{tabular}{|c|c|c|c|c|c|}
\hline & & Univariate & & Multivariate & \\
\hline Risk Factor 1 & Deterioration & HR (95\% CI) & $p$-Value & HR (95\% CI) & $p$-Value \\
\hline \multicolumn{6}{|l|}{ Baseline $^{2}$} \\
\hline Physical function & & $0.70(0.49-1.01)$ & 0.055 & & \\
\hline Appetite loss & & $1.30(1.01-1.66)$ & 0.043 & 1.30 (1.01-1.66) & 0.043 \\
\hline $\begin{array}{c}\text { Chemotherapy } \\
\text { side effects } \\
\text { Change }\end{array}$ & & $1.15(0.51-2.60)$ & 0.739 & & \\
\hline Weight loss & $\begin{array}{l}\text { No } \\
\text { Yes }\end{array}$ & $2.67(0.46,15.28)$ & 0.272 & & \\
\hline
\end{tabular}

${ }^{1}$ differing from overall collective only ${ }^{2}$ HRs calculated for every $20 \%$.

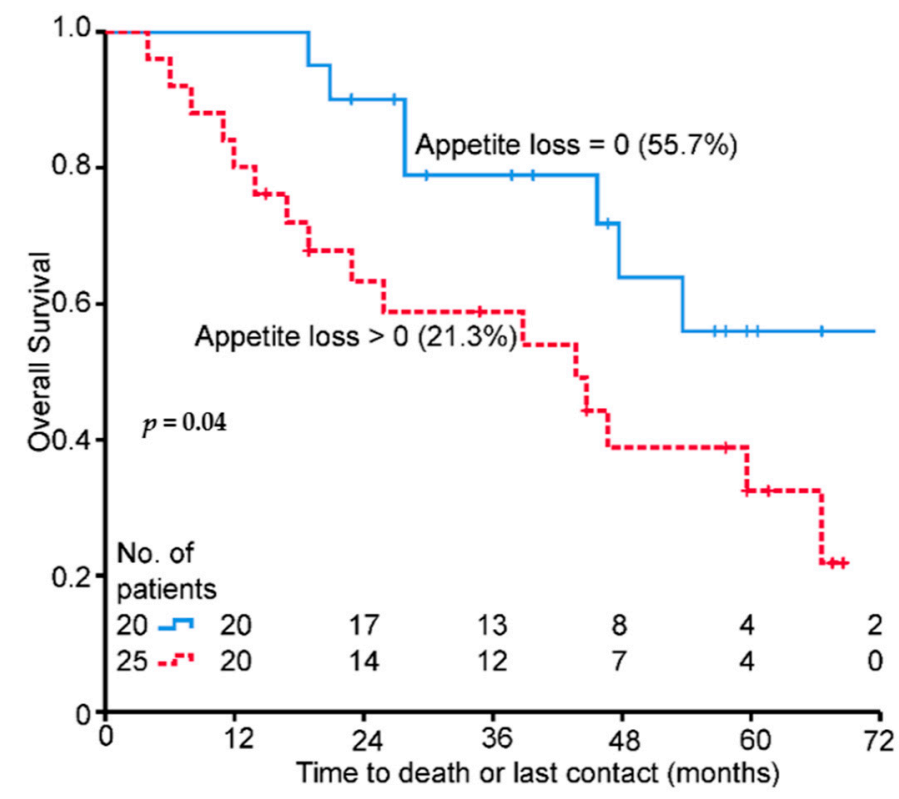

Figure 3. Baseline score Kaplan-Meier plots for overall survival and appetite loss, M1 patients only, 72-month OS\% in brackets. 

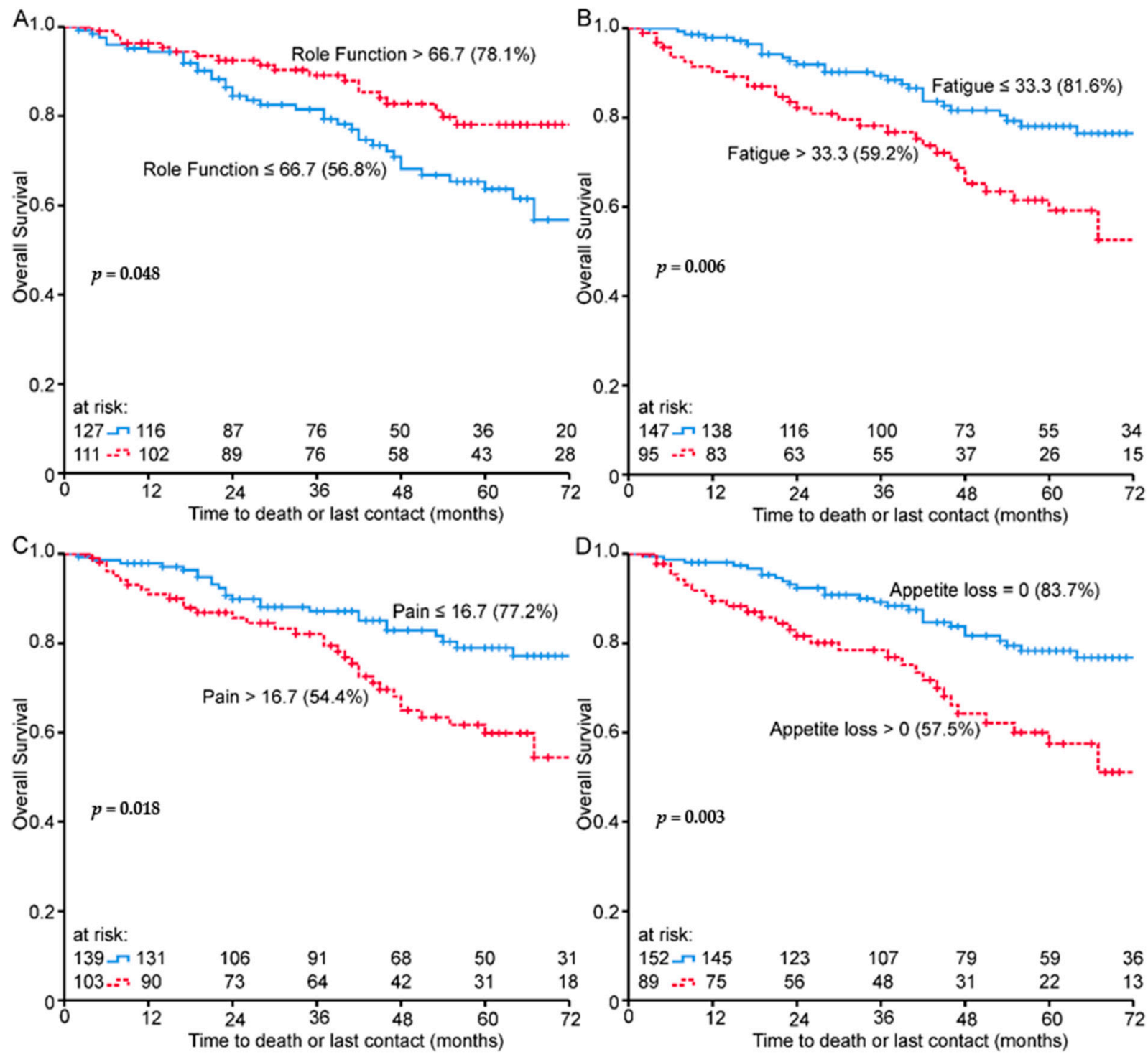

Figure 4. Baseline scores Kaplan-Meier plots for overall survival and (A) role function, (B) fatigue, (C) pain and (D) appetite loss, 72-month OS\% in brackets.

Table 4. Overall survival of age-adjusted hazard ratios for baseline QLQ C30 and QLQ CR38.

\begin{tabular}{cccccc}
\hline & & Univariate & & Multivariate \\
\hline Risk Factor ${ }^{\mathbf{1}}$ & Mean (SD) & HR (95\% CI) & $p$-Value & HR (95\% CI) & $p$-Value \\
\hline Gender & & $1.19(0.91-1.56)$ & 0.208 & $1.46(1.07-2.01)$ & 0.011 \\
QLQ C30 & & $0.70(0.59-0.84)$ & $<0.001$ & $0.71(0.57-0.88)$ & 0.002 \\
Physical function & $79.67(22.30)$ & $0.83(0.71-0.97)$ & 0.02 & $1.13(0.86-1.48)$ & 0.375 \\
Role function & $69.26(30.33)$ & $0.96(0.79-1.16)$ & 0.669 & & \\
Emotional function & $64.02(25.95)$ & $0.84(0.67-1.06)$ & 0.15 & & \\
Cognitive function & $84.30(21.71)$ & $1.02(0.85-1.21)$ & 0.863 & & \\
Social function & $66.32(30.38)$ & $0.89(0.73-1.09)$ & 0.248 & $0.84(0.58-1.21)$ & 0.351 \\
Global health & $58.95(22.30)$ & $1.32(1.10-1.58)$ & 0.003 & $1.07(0.73-1.58)$ & 0.732 \\
Fatigue & $36.29(27.74)$ & $1.36(1.04-1.76)$ & 0.024 & $1.11(0.89-1.39)$ & 0.369 \\
Nausea and & $6.30(15.61)$ & $1.26(1.07-1.50)$ & 0.004 & &
\end{tabular}


Table 4. Cont.

\begin{tabular}{|c|c|c|c|c|c|}
\hline & & Univariate & & Multivariate & \\
\hline Risk Factor ${ }^{1}$ & Mean (SD) & HR (95\% CI) & $p$-Value & HR (95\% CI) & $p$-Value \\
\hline Dyspnea & $18.67(27.33)$ & $1.24(1.03-1.50)$ & 0.021 & $1.23(0.99-1.53)$ & 0.068 \\
\hline Insomnia & $33.61(33.20)$ & $1.12(0.95-1.32)$ & 0.194 & & \\
\hline Appetite loss & $19.08(28.79)$ & $1.34(1.14-1.58)$ & $<0.001$ & $1.18(0.93-1.50)$ & 0.171 \\
\hline Constipation & $14.70(28.29)$ & $0.86(0.68-1.10)$ & 0.225 & & \\
\hline Diarrhea & $34.45(36.01)$ & $1.15(0.97-1.34)$ & 0.078 & & \\
\hline $\begin{array}{l}\text { Financial } \\
\text { difficulties }\end{array}$ & $21.52(31.61)$ & $0.99(0.82-1.20)$ & 0.944 & & \\
\hline \multicolumn{6}{|l|}{ QLQ CR38 } \\
\hline Body Image & $77.81(25.78)$ & $0.85(0.69-1.05)$ & 0.125 & & \\
\hline Sexual function & $71.72(29.36)$ & $1.11(0.88-1.41)$ & 0.369 & & \\
\hline Future prospects & $34.18(33.75)$ & $1.01(0.85-1.18)$ & 0.949 & & \\
\hline $\begin{array}{l}\text { Micturition } \\
\text { problems }\end{array}$ & $15.75(10.86)$ & $1.33(0.83-2.13)$ & 0.241 & & \\
\hline $\begin{array}{l}\text { Chemotherapy } \\
\text { side effects }\end{array}$ & $7.61(9.52)$ & $1.48(0.79-2.79)$ & 0.221 & & \\
\hline $\begin{array}{l}\text { Gastrointestinal } \\
\text { problems }\end{array}$ & $10.93(9.55)$ & $0.90(0.44-1.82)$ & 0.769 & & \\
\hline $\begin{array}{l}\text { Male sexual } \\
\text { problems }^{2}\end{array}$ & $18.77(19.31)$ & $1.60(1.07-2.40)$ & 0.021 & & \\
\hline $\begin{array}{l}\text { Defecation } \\
\text { problems }\end{array}$ & $16.13(10.83)$ & $0.85(0.48-1.51)$ & 0.583 & & \\
\hline Weight loss & $21.48(29.85)$ & $1.22(1.02-1.47)$ & 0.033 & $1.04(0.81-1.34)$ & 0.756 \\
\hline
\end{tabular}

${ }^{1} \mathrm{HRs}$ calculated for every $20 \%,{ }^{2}$ Only calculated for male patients, not included in multivariate.

Table 5. Overall survival of age-adjusted hazard ratios for change QLQ C30 and QLQ CR38.

\begin{tabular}{|c|c|c|c|c|c|}
\hline & & Univariate & & Multivariate & \\
\hline Risk Factor ${ }^{1}$ & Deterioration & HR (95\% CI) & $p$-Value & HR $(95 \%$ CI) & $p$-Value \\
\hline \multicolumn{6}{|l|}{ QLQ C30 } \\
\hline \multirow{2}{*}{ Physical function } & No & & & & \\
\hline & Yes & $1.09(0.33-3.64)$ & 0.883 & & \\
\hline \multirow{2}{*}{ Role function } & No & & & & \\
\hline & Yes & $0.78(0.23-2.60)$ & 0.682 & & \\
\hline \multirow{2}{*}{ Emotional function } & No & & & & \\
\hline & Yes & $0.95(0.40-2.23)$ & 0.902 & & \\
\hline \multirow{2}{*}{ Cognitive function } & No & & & & \\
\hline & Yes & $0.54(0.22-1.34)$ & 0.185 & & \\
\hline \multirow{2}{*}{ Social function } & No & & & & \\
\hline & Yes & $0.61(0.27-1.40)$ & 0.246 & & \\
\hline \multirow{2}{*}{ Global health } & No & & & & \\
\hline & Yes & $1.40(0.66-2.97)$ & 0.376 & & \\
\hline \multirow{2}{*}{ Fatigue } & No & & & & \\
\hline & Yes & $0.52(0.24-1.11)$ & 0.09 & & \\
\hline \multirow{2}{*}{$\begin{array}{l}\text { Nausea and } \\
\text { vomiting }\end{array}$} & No & & & & \\
\hline & Yes & $0.90(0.39-2.08)$ & 0.801 & & \\
\hline \multirow{2}{*}{ Pain } & No & & & & \\
\hline & Yes & $0.82(0.38-1.73)$ & 0.593 & & \\
\hline \multirow{2}{*}{ Dyspnea } & No & & & & \\
\hline & Yes & $0.64(0.25-1.64)$ & 0.35 & & \\
\hline \multirow{2}{*}{ Insomnia } & No & & & & \\
\hline & Yes & $0.93(0.43-2.02)$ & 0.857 & & \\
\hline \multirow{2}{*}{ Appetite loss } & No & & & & \\
\hline & Yes & $0.53(0.24-1.17)$ & 0.115 & & \\
\hline
\end{tabular}


Table 5. Cont.

\begin{tabular}{|c|c|c|c|c|c|}
\hline & & Univariate & & Multivariate & \\
\hline Risk Factor ${ }^{1}$ & Deterioration & HR (95\% CI) & $p$-Value & HR (95\% CI) & $p$-Value \\
\hline \multirow{2}{*}{ Constipation } & $\mathrm{No}$ & & & & \\
\hline & Yes & $1.85(0.81-4.21)$ & 0.144 & & \\
\hline \multirow{2}{*}{ Diarrhea } & No & & & & \\
\hline & Yes & $0.44(0.20-0.98)$ & 0.044 & $0.34(0.13-0.93)$ & 0.035 \\
\hline Financial & No & & & & \\
\hline difficulties & Yes & $1.50(0.69-3.29)$ & 0.309 & & \\
\hline \multicolumn{6}{|l|}{$Q L Q C R 38$} \\
\hline \multirow{2}{*}{ Body Image } & No & & & & \\
\hline & Yes & $0.56(0.26-1.19)$ & 0.13 & & \\
\hline \multirow{2}{*}{ Sexual function } & No & & & & \\
\hline & Yes & $3.60(1.36-9.57)$ & 0.01 & 4.05 (1.47-11.11) & 0.007 \\
\hline \multirow{2}{*}{ Future prospects } & No & & & & \\
\hline & Yes & $0.60(0.18-2.02)$ & 0.41 & & \\
\hline \multirow{2}{*}{$\begin{array}{c}\text { Micturition } \\
\text { problems }\end{array}$} & No & & & & \\
\hline & Yes & $1.04(0.48-2.26)$ & 0.923 & & \\
\hline \multirow{2}{*}{ Chemo side effects } & No & & & & \\
\hline & Yes & $0.83(0.39-1.80)$ & 0.642 & & \\
\hline \multirow{2}{*}{$\begin{array}{l}\text { Gastrointestinal } \\
\text { problems }\end{array}$} & No & & & & \\
\hline & Yes & $0.56(0.26-1.20)$ & 0.133 & & \\
\hline \multirow{2}{*}{$\begin{array}{l}\text { Male sexual } \\
\text { problems } 1\end{array}$} & No & & & & \\
\hline & Yes & $0.82(0.27-2.52)$ & 0.733 & & \\
\hline \multirow{2}{*}{$\begin{array}{l}\text { Defecation } \\
\text { problems }\end{array}$} & $\mathrm{No}$ & & & & \\
\hline & Yes & $1.84(0.57-5.88)$ & 0.307 & & \\
\hline \multirow{2}{*}{ Weight loss } & No & & & & \\
\hline & Yes & $0.33(0.14-0.77)$ & 0.01 & $0.32(0.10-0.97)$ & 0.044 \\
\hline
\end{tabular}




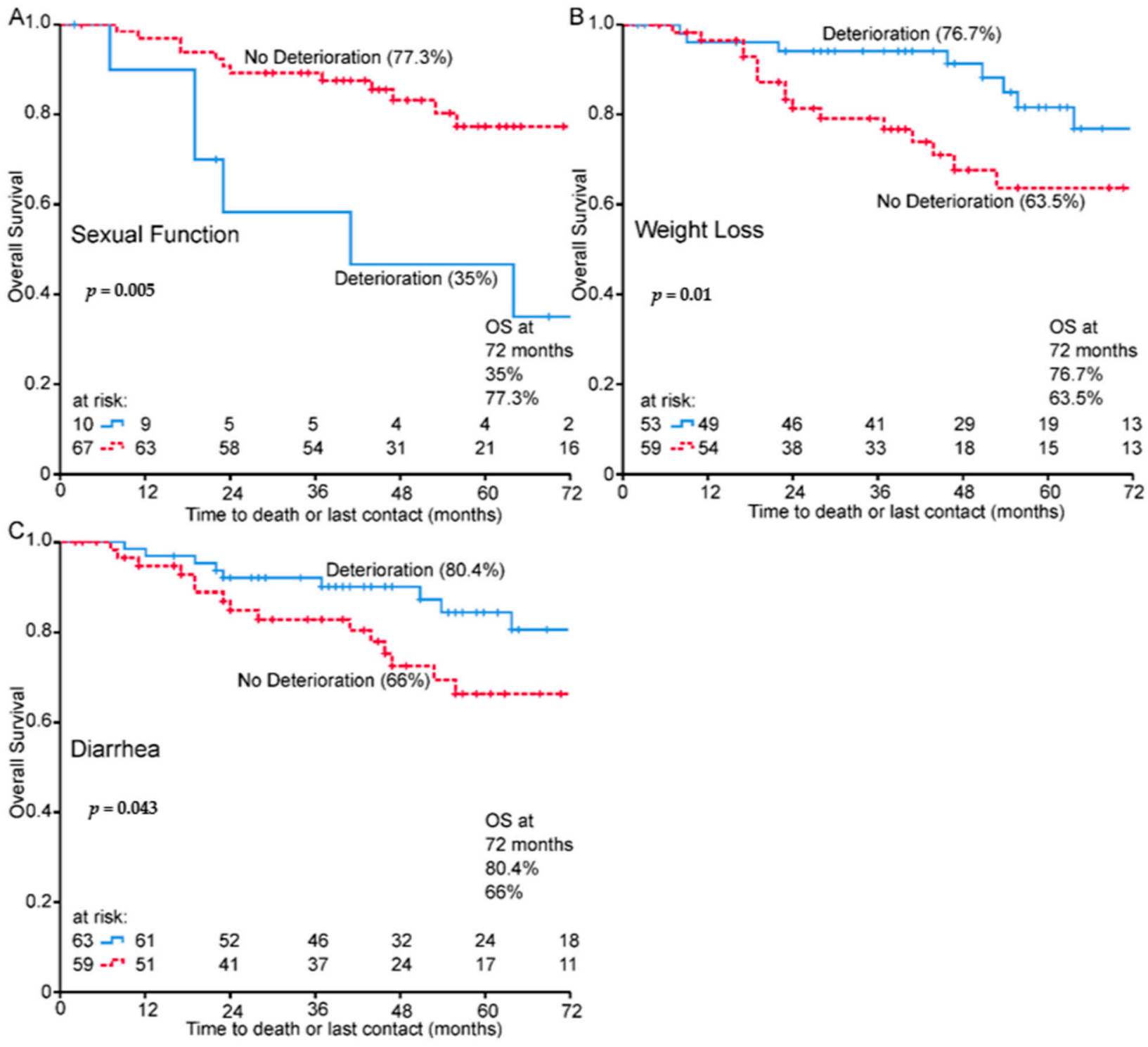

Figure 5. Change scores treatment Kaplan-Meier charts for overall survival and (A) sexual function, (B) weight loss and (C) diarrhea, 72-month OS\% in brackets.

\section{Discussion}

This study investigated the prognostic value of EORTC QLQ C30 and CR38 data for patients with rectal cancer. A particular focus was on patients with metastases who performed slightly better in overall survival than expected. Five year overall survival is reported with $62 \%$ in Germany [26], whereas our cohort had 70.5\%.

The metastatic patients had little to no significant difference in most QoL domains. To the best of our knowledge, this has not been previously reported. They differed in only four domains. Baseline scores for physical function, loss of appetite, side effects of chemotherapy, and change scores for weight loss. Regarding survival prediction, only appetite loss (HR $1.3095 \% \mathrm{CI}=1.01-1.66, p=0.043$ ) was prognostically relevant. Metastatic status has previously been associated with worse QoL in various cancer types before $[27,28]$. Contrary to intuitive expectation, the bad news of metastatic disease does not seem to clearly affect QoL. Cancer diagnosis itself is associated with poorer self-reported QoL [29]. However, positive metastatic status was strongly associated with overall survival (HR 3.81, $95 \% \mathrm{CI}=2.25-6.47, p<0.001)$, which is consistent with previous reports $[25,30,31]$. Oth- 
erwise, resectable metastases are no longer associated with a significantly worse prognosis [32]. Efficace et al. [5] have shown that social function is prognostic in metastatic colorectal cancer beyond several biomedical parameters, a result we could not reproduce. The difference in HRQoL in metastatic vs. non-metastatic patients should be reproduced by other research groups. Further research is needed to confirm or reject this finding.

Regarding the predictive power of the HRQoL data for the entire cohort, we were able to support our assumptions. In univariate analysis of baseline QoL scores, physical function, role function, fatigue, nausea and vomiting, pain, dyspnea, appetite loss, male sexual problems, and weight loss were prognostic for survival. All of these factors have been described as prognostically relevant in previous studies, although sometimes in different combinations $[4,5,7,11,33,34]$. Physical function, role function, fatigue, pain, dyspnea, insomnia, and appetite loss have also been described as prognostic in other tumor types $[15,25,30,35,36]$. Multivariate analysis in our study leaves physical function and male gender as significant prognostic QoL factors. In Germany, colorectal cancer affects more men than women (10-year prevalence 196,100 and 159,500, respectively). The relative 10-year survival rate in Germany is $60 \%$ for women, but $56 \%$ for men [26]. Our results support a worse prognosis for male patients.

The change scores for sexual function, weight loss, and diarrhea were predictive for overall survival in our cohort, interestingly with a longer OS for patients with more diarrhea and more weight loss. Better sexual function has been previously described as a positive prognostic factor [37]. This study cannot provide an explanation for the unexpected association of an increase in diarrhea and weight loss with longer patient survival.

\subsection{Strengths and Weaknesses}

A homogeneous cohort with a uniform treatment regimen was studied. Valid and reliable tools were used to prospectively measure HRQoL. In addition, reliable survival data were available. The study itself relied on data that were not collected to test a specific intervention. The cohort was consecutively surveyed and mainly patients were included speaking German and therefore cannot be representative of all colorectal cancer patients. Due to nature of the HRQoL data, it is not a randomized controlled trial and therefore no causal relationships can be derived. The data were collected in a time frame around the administration of therapy, so disease- or therapy-related impairments in quality of life late in the course of the disease are not detected.

\subsection{Comparability}

A variety of correlations between HRQoL and OS have been reported over the years, but it remains difficult to identify individual predictors [9]. QoL data tend to act as surrogates for underlying prognostic factors [38]. It is undisputed that HRQoL provides valuable information. A meta-analysis of 30 randomized controlled trials from the EORTC [39] shows physical function, nausea and vomiting, pain, and appetite loss as prognostic factors in colorectal cancer that are close to our results. The persistent inconsistency of results leads to the assumption that there may not be a single predictor of OS in the HRQoL sphere. Differences in study design particularly in cohort selection, timing of QoL assessment, therapy, stage of disease, and control for other parameters make it difficult to reproduce findings [40]. However, this does not undermine the importance of QoL measurement in cancer trials.

\section{Conclusions}

Contrary to our expectations, patients with metastasis report an equally good quality of life as cured patients with rectal carcinoma. Future research is needed to confirm this finding. It should be noted that HRQoL was collected in relatively close proximity to therapy. Both baseline and change score of EORTC QLQ C30 and CRC38 provide prognostic information in patients with rectal carcinoma. Our results demonstrate the value of PROs 
when assessing HRQoL with EORTC questionnaires. The specific domains found to be of prognostically relevant provide emphasis areas for intervention and future trials.

Author Contributions: F.F. and L.D. conceptualized the manuscript. F.F. investigated the findings. F.F. performed the analysis. L.D., F.L., S.R. and R.F. provided the resources. L.D., M.H. and R.F. supervised the findings. F.F. wrote the first draft of the manuscript. F.F., M.H., S.R. and L.D. have been involved in writing and revision of the manuscript. All authors have read and agreed to the published version of the manuscript.

Funding: This research received no external funding.

Institutional Review Board Statement: The Ethics Review Committee of the University Hospital Erlangen approved the study including the use of individual patient data. Ethics committee approval number 3745.

Informed Consent Statement: All patients gave their written informed consent to the scientific processing of their data.

Data Availability Statement: Data are available from the authors upon reasonable request.

Conflicts of Interest: The authors declare no conflict of interest.

Disclosure: The present work was performed in (partial) fulfillment of the requirements for obtaining the degree "Dr. med".

$\begin{array}{ll}\text { Abbreviations } & \\ \text { PROs } & \text { patient reported outcomes } \\ \text { HRQoL } & \text { health related quality of life } \\ \text { QoL } & \text { quality of life } \\ \text { OS } & \text { overall survival } \\ \text { EORTC } & \text { European organization for research and treatment of cancer } \\ \text { QLQ } & \text { quality of life questionnaire }\end{array}$

\section{References}

1. Byrne, C.; Griffin, A.; Blazeby, J.; Conroy, T.; Efficace, F. Health-related quality of life as a valid outcome in the treatment of advanced colorectal cancer. Eur. J. Surg. Oncol. 2007, 33 (Suppl. 2), S95-S104. [CrossRef] [PubMed]

2. Haussmann, J.; Nestle-Kraemling, C.; Bolke, E.; Wollandt, S.; Speer, V.; Djiepmo Njanang, F.J.; Tamaskovics, B.; Gerber, P.A.; Orth, K.; Ruckhaeberle, E.; et al. Long-term quality of life after preoperative radiochemotherapy in patients with localized and locally advanced breast cancer. Strahlenther. Onkol. 2020, 196, 386-397. [CrossRef]

3. Steinmann, D.; Vordermark, D.; Gerstenberg, W.; Aschoff, R.; Gharbi, N.; Muller, A.; Schafer, C.; Theodorou, M.; Wypior, H.J.; Geinitz, H.; et al. Quality of life in patients with limited (1-3) brain metastases undergoing stereotactic or whole brain radiotherapy: A prospective study of the degro qol working group. Strahlenther. Onkol. 2020, 196, 48-57. [CrossRef] [PubMed]

4. Maisey, N.R.; Norman, A.; Watson, M.; Allen, M.J.; Hill, M.E.; Cunningham, D. Baseline quality of life predicts survival in patients with advanced colorectal cancer. Eur. J. Cancer 2002, 38, 1351-1357. [CrossRef]

5. Efficace, F.; Bottomley, A.; Coens, C.; Van Steen, K.; Conroy, T.; Schoffski, P.; Schmoll, H.; Van Cutsem, E.; Kohne, C.H. Does a patient's self-reported health-related quality of life predict survival beyond key biomedical data in advanced colorectal cancer? Eur. J. Cancer 2006, 42, 42-49. [CrossRef]

6. Jörling, M.; Rutzner, S.; Hecht, M.; Fietkau, R.; Distel, L. Deterioration of health-related quality of life scores under treatment predicts longer survival. BioMed Res. Int. 2020, 2020, 1-10. [CrossRef]

7. Bonnetain, F.; Borg, C.; Adams, R.R.; Ajani, J.A.; Benson, A.; Bleiberg, H.; Chibaudel, B.; Diaz-Rubio, E.; Douillard, J.Y.; Fuchs, C.S.; et al. How health-related quality of life assessment should be used in advanced colorectal cancer clinical trials. Ann. Oncol. 2017, 28, 2077-2085. [CrossRef]

8. Gotay, C.C.; Kawamoto, C.T.; Bottomley, A.; Efficace, F. The prognostic significance of patient-reported outcomes in cancer clinical trials. J. Clin. Oncol. 2008, 26, 1355-1363. [CrossRef]

9. Grande, G.E.; Farquhar, M.C.; Barclay, S.I.; Todd, C.J. Quality of life measures (eortc qlq-c30 and sf-36) as predictors of survival in palliative colorectal and lung cancer patients. Palliat. Support. Care 2009, 7, 289-297. [CrossRef]

10. Wong, C.K.; Law, W.L.; Wan, Y.F.; Poon, J.T.; Lam, C.L. Health-related quality of life and risk of colorectal cancer recurrence and all-cause death among advanced stages of colorectal cancer 1-year after diagnosis. BMC Cancer 2014, 14, 337. [CrossRef]

11. Fournier, E.; Jooste, V.; Woronoff, A.S.; Quipourt, V.; Bouvier, A.M.; Mercier, M. Health-related quality of life is a prognostic factor for survival in older patients after colorectal cancer diagnosis: A population-based study. Dig. Liver Dis. 2016, 48, 87-93. [CrossRef] [PubMed]

12. Osthus, A.A.; Aarstad, A.K.; Olofsson, J.; Aarstad, H.J. Health-related quality of life scores in long-term head and neck cancer survivors predict subsequent survival: A prospective cohort study. Clin. Otolaryngol. 2011, 36, 361-368. [CrossRef] [PubMed] 
13. Coates, A.S.; Hurny, C.; Peterson, H.F.; Bernhard, J.; Castiglione-Gertsch, M.; Gelber, R.D.; Goldhirsch, A. Quality-of-life scores predict outcome in metastatic but not early breast cancer. International breast cancer study group. J. Clin. Oncol. 2000, 18, 3768-3774. [CrossRef] [PubMed]

14. Efficace, F.; Biganzoli, L.; Piccart, M.; Coens, C.; Van Steen, K.; Cufer, T.; Coleman, R.E.; Calvert, H.A.; Gamucci, T.; Twelves, C.; et al. Baseline health-related quality-of-life data as prognostic factors in a phase iii multicentre study of women with metastatic breast cancer. Eur. J. Cancer 2004, 40, 1021-1030. [CrossRef]

15. Lee, C.K.; Stockler, M.R.; Coates, A.S.; Gebski, V.; Lord, S.J.; Simes, R.J.; Australian New Zealand Breast Cancer Trials, G. Self-reported health-related quality of life is an independent predictor of chemotherapy treatment benefit and toxicity in women with advanced breast cancer. Br. J. Cancer 2010, 102, 1341-1347. [CrossRef] [PubMed]

16. Haraldseide, L.M.; Jakola, A.S.; Solheim, O.; Sagberg, L.M. Does preoperative health-related quality of life predict survival in high-grade glioma patients?-A prospective study. Br. J. Neurosurg. 2019, 34, 28-34. [CrossRef]

17. Sauer, R.; Becker, H.; Hohenberger, W.; Rodel, C.; Wittekind, C.; Fietkau, R.; Martus, P.; Tschmelitsch, J.; Hager, E.; Hess, C.F.; et al. Preoperative versus postoperative chemoradiotherapy for rectal cancer. N. Engl. J. Med. 2004, 351, 1731-1740. [CrossRef]

18. Li, Y.; Wang, J.; Ma, X.; Tan, L.; Yan, Y.; Xue, C.; Hui, B.; Liu, R.; Ma, H.; Ren, J. A review of neoadjuvant chemoradiotherapy for locally advanced rectal cancer. Int. J. Biol. Sci. 2016, 12, 1022-1031. [CrossRef]

19. van der Geest, L.G.; Lam-Boer, J.; Koopman, M.; Verhoef, C.; Elferink, M.A.; de Wilt, J.H. Nationwide trends in incidence, treatment and survival of colorectal cancer patients with synchronous metastases. Clin. Exp. Metastasis 2015, 32, 457-465. [CrossRef]

20. Folprecht, G.; Grothey, A.; Alberts, S.; Raab, H.R.; Kohne, C.H. Neoadjuvant treatment of unresectable colorectal liver metastases: Correlation between tumour response and resection rates. Ann. Oncol. 2005, 16, 1311-1319. [CrossRef]

21. Field, K.; Lipton, L. Metastatic colorectal cancer-past, progress and future. World J. Gastroenterol. 2007, 13, 3806-3815. [CrossRef] [PubMed]

22. Siegel, R.L.; Miller, K.D.; Jemal, A. Cancer statistics, 2015. CA Cancer J. Clin. 2015, 65, 5-29. [CrossRef] [PubMed]

23. Aaronson, N.K.; Ahmedzai, S.; Bergman, B.; Bullinger, M.; Cull, A.; Duez, N.J.; Filiberti, A.; Flechtner, H.; Fleishman, S.B.; de Haes, J.C.; et al. The european organization for research and treatment of cancer qlq-c30: A quality-of-life instrument for use in international clinical trials in oncology. J. Natl. Cancer Inst. 1993, 85, 365-376. [CrossRef]

24. Sprangers, M.A.; te Velde, A.; Aaronson, N.K. The construction and testing of the eortc colorectal cancer-specific quality of life questionnaire module (qlq-cr38). European organization for research and treatment of cancer study group on quality of life. Eur. J. Cancer 1999, 35, 238-247. [CrossRef]

25. Sternby Eilard, M.; Hagstrom, H.; Mortensen, K.E.; Wilsgaard, T.; Vagnildhaug, O.M.; Dajani, O.; Stal, P.; Rizell, M. Quality of life as a prognostic factor for survival in hepatocellular carcinoma. Liver Int. 2017, 38, 885-894. [CrossRef]

26. Krebs in Deutschland Für 2015/2016, 12th ed.; Robert Koch-Institut (Hrsg) und Die Gesellschaft der Epidemiologischen Krebsregister in Deutschland e.V. Publisher: Berlin, Germany, 2019.

27. Hamer, J.; McDonald, R.; Zhang, L.; Verma, S.; Leahey, A.; Ecclestone, C.; Bedard, G.; Pulenzas, N.; Bhatia, A.; Chow, R.; et al. Quality of life (qol) and symptom burden (sb) in patients with breast cancer. Support. Care Cancer 2017, 25, 409-419. [CrossRef] [PubMed]

28. Picozzi, V.; Narayanan, S.; Henry Hu, X.; Vacirca, J. Health-related quality of life in patients with metastatic pancreatic cancer. J. Gastrointest. Cancer 2017, 48, 103-109. [CrossRef]

29. Williams, K.; Jackson, S.E.; Beeken, R.J.; Steptoe, A.; Wardle, J. The impact of a cancer diagnosis on health and well-being: A prospective, population-based study. Psychooncology 2016, 25, 626-632. [CrossRef]

30. Vickers, M.M.; Lee, C.; Tu, D.; Wheatley-Price, P.; Parulekar, W.; Brundage, M.D.; Moore, M.J.; Au, H.; O'Callaghan, C.J.; Jonker, D.J.; et al. Significance of baseline and change in quality of life scores in predicting clinical outcomes in an international phase iii trial of advanced pancreatic cancer: Ncic ctg pa.3. Pancreatology 2016, 16, 1106-1112. [CrossRef]

31. Brierley, J.; Gospodarowicz, M.K.; Wittekind, C. Tnm Classification of Malignant Tumours, 8th ed.; John Wiley \& Sons, Inc.: Chichester, UK; Hoboken, NJ, USA, 2017.

32. Alberts, S.R. Update on the optimal management of patients with colorectal liver metastases. Crit. Rev. Oncol. Hematol. 2012, 84, 59-70. [CrossRef]

33. Efficace, F.; Innominato, P.F.; Bjarnason, G.; Coens, C.; Humblet, Y.; Tumolo, S.; Genet, D.; Tampellini, M.; Bottomley, A.; Garufi, C.; et al. Validation of patient's self-reported social functioning as an independent prognostic factor for survival in metastatic colorectal cancer patients: Results of an international study by the chronotherapy group of the european organisation for research and treatment of cancer. J. Clin. Oncol. 2008, 26, 2020-2026. [PubMed]

34. Braun, D.P.; Gupta, D.; Grutsch, J.F.; Staren, E.D. Can changes in health related quality of life scores predict survival in stages iii and iv colorectal cancer? Health Qual. Life Outcomes 2011, 9, 62. [CrossRef]

35. Osthus, A.A.; Aarstad, A.K.; Olofsson, J.; Aarstad, H.J. Prediction of survival by pretreatment health-related quality-of-life scores in a prospective cohort of patients with head and neck squamous cell carcinoma. JAMA Otolaryngol. Head Neck Surg. 2013, 139, 14-20. [CrossRef] [PubMed]

36. Efficace, F.; Bottomley, A.; Smit, E.F.; Lianes, P.; Legrand, C.; Debruyne, C.; Schramel, F.; Smit, H.J.; Gaafar, R.; Biesma, B.; et al. Is a patient's self-reported health-related quality of life a prognostic factor for survival in non-small-cell lung cancer patients? A multivariate analysis of prognostic factors of eortc study 08975. Ann. Oncol. 2006, 17, 1698-1704. [CrossRef] [PubMed] 
37. Camilleri-Brennan, J.; Steele, R.J. Prospective analysis of quality of life and survival following mesorectal excision for rectal cancer. Br. J. Surg. 2001, 88, 1617-1622. [CrossRef] [PubMed]

38. Coates, A.; Porzsolt, F.; Osoba, D. Quality of life in oncology practice: Prognostic value of eortc qlq-c30 scores in patients with advanced malignancy. Eur. J. Cancer 1997, 33, 1025-1030. [CrossRef]

39. Quinten, C.; Martinelli, F.; Coens, C.; Sprangers, M.A.; Ringash, J.; Gotay, C.; Bjordal, K.; Greimel, E.; Reeve, B.B.; Maringwa, J.; et al. A global analysis of multitrial data investigating quality of life and symptoms as prognostic factors for survival in different tumor sites. Cancer 2014, 120, 302-311. [CrossRef]

40. Osoba, D. Health-related quality of life and cancer clinical trials. Ther. Adv. Med. Oncol. 2011, 3, 57-71. [CrossRef] 